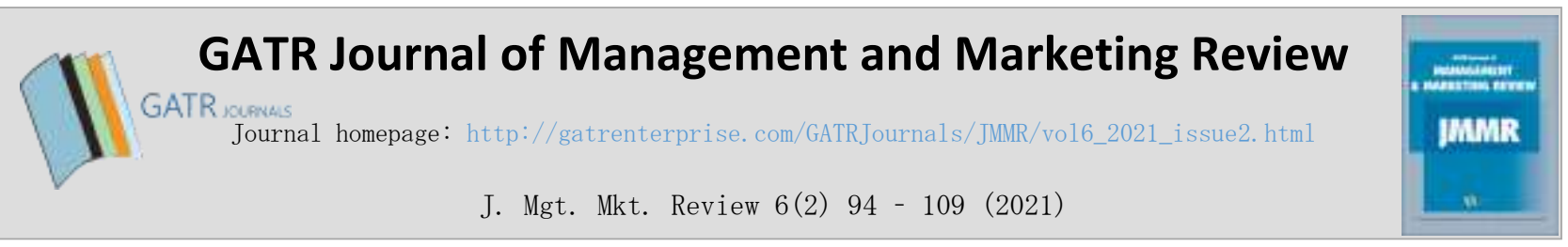

\title{
Home Office and Its Influence on Employee Motivation
}

\author{
Kateřina Bočková ${ }^{*}$, Daniel Lajčin ${ }^{2}$ \\ ${ }^{1,2}$ DTI University, Department of management and economics, Sládkovičova 533/20, 01841 Dubnica and Váhom, Slovakia
}

\begin{abstract}
Objective - The aim of the paper is to answer the research question, "whether and how home office work can have an impact on employee motivation." Using partial questions, we found out how the interviewed employees perceive work in the form of a home office, what they see as advantages and disadvantages, or what motivates or demotivates them in this area and how important the home office is for them in the field of motivation.

Methodology/Technique - For the implementation of the survey, we chose a qualitative method in the form of semistructured interviews. All interviews were arranged in advance and took place in an informal atmosphere, most often in a home environment. The interviews were recorded on a recording device with the consent of the respondents, for the possibility of data processing and subsequent analysis. The selection of respondents was carried out by the method of intentional selection. The research sample involved ninety respondents who had specific experience with working from home, which meant that they currently used work from home, i.e., home office as a benefit, standard or primary place of work. One interview was conducted with each respondent in the time range of 25 to 35 minutes.

Findings - Within the research, several areas were confirmed, which are mentioned by various authors in the theoretical part of the presented paper. There is a positive perception of home office employees in the area of saving time, or the feeling of freedom. In the negative case, and thus potentially demotivating, phenomena of employees in the area of social isolation was most significantly confirmed. The issue of procrastination mentioned by the respondents in several cases could also be mentioned as confirmatory and existing in-home office. The frustration with low home office efficiency was not mentioned by the respondents, on the contrary, some stated that they found their work from home more efficient than in the office. The results of the presented research show that it would be a mistake to look at the home office only from one side.

Novelty - Although it could be said that the positives of this type of work performance to motivate employees outweigh the negatives, this ratio may vary significantly from employee to employee, especially depending on the specific and current conditions, which may also change significantly within the time. The presented paper was processed as an output of the project VEGA 1/0021/21 Identification of motivation factors for the performance of certified project managers working in the home office during the pandemic of COVID 19.
\end{abstract}

Type of Paper: Empirical.

JEL Classification: J53, M54

Keywords: Home office, homeworking, motivation, demotivation, self-motivation, procrastination, management, personal management, employment.

Reference to this paper should be made as follows: Bočková, K; Lajčin, D. (2021). Home Office and Its Influence on Employee Motivation, J. Mgt. Mkt. Review, 6(2) 94 - 109. https://doi.org/10.35609/jmmr.2021.6.2(1)

\section{Introduction}

Every adult in the productive age (unless he is a retired person, unemployed, or a person supported by a parent) works. For most of these people, it is true, or until recently, that they come to a place away from home to pursue their professional activities.

\footnotetext{
Paper Info: Revised: March 12, 2021

Accepted: June 30, 2021

*Corresponding author: Kateřina Bočková

E-mail: bockova@dti.sk

Affiliation: DTI University, Slovakia
} 
At present, the topic of job flexibility is a current and often discussed topic, both on the part of employees and employers. Today's relatively dynamic time affected by the COVID-19 pandemic encourages, or even directly forces, employers and employees to look for solutions that are often significantly different from previously established "traditional" ways of doing work. In connection with the place of work itself, we often talk about employment in the form of a home office.

This statement can be relatively well demonstrated and supported by the result of a search on one of the most important personal internet portals in the Czech Republic www.jobs.cz, where it is possible to find out that jobs offered contain the keyword home office in 4,109 cases or advertisements, for which the employer offered full or partial performance of work in this form. The given data are from 15.4.2021 (in: jobs.cz: Job offers, 2021).

There are several variants and various modifications of forms of work outside the office. Some companies use, enable or even prefer working from home in the form of a home office. In practice, we often encounter different views on this form of work, both in terms of positive benefits and negatives and risks. In practice, there is probably no uniform view of this issue, both on the side of employers and management and employees. Working from home in the form of a home office shows certain specifics and places specific and different demands compared to "traditional" work in the office or in another place designated by the employer to perform work.

The problem may be not only the decision itself whether to allow and whether to use work from home for employees, but also the decision on which job positions and with what job description are suitable for the mentioned form of work performance. The place of work most likely has a significant effect on the motivation of employees and management. The question is whether and under what conditions positive motivation prevails.

The issue of work organization and motivation of employees working from home deepens with the extension of the time when employees work from home due to the global COVID-19 pandemic, and this is the reason why the presented paper focuses on this topic.

\section{Literature Review}

Russo et al. (2021) state that the topic of labor flexibility is one of the relatively new topics in the Czech context, which began to be discussed to a greater extent only in connection with the transformation of the labor market after 1989. Compared to the previous organization characterized by high job security, low performance orientation and a lifetime employment model, new ways of organizing working time, new forms of employment and the phenomenon of unemployment began to emerge in response to new pressures and threats from globalization. In connection with the growing pressure on the competitiveness of companies, emphasis began to be placed on labor flexibility, maximum performance, and labor productivity.

Nový \& Surynek et al. (2006, p. 235) point out that new forms of employment "place extremely high demands on the personality of the worker, not only in terms of his material knowledge and skills, but especially on the strength of his personality. Thus, the demands on his ability to orient himself well, to succeed as an individual in a complicated, confusing competitive, and therefore difficult world of work, his strength to overcome obstacles, survive the alternation of periods of individually successful and unsuccessful and find a suitable lifestyle." Mehnert-Theuerkauf (2020) adds that some macroeconomic and social factors also exert pressure on the individual and his flexibility, such as rising unemployment, rising immigration, globalization, an aging population associated with prolonged retirement or pension issues. Therefore, the flexibility of the organization and employees is both a necessity, but also an important prerequisite for success.

Furthermore, Dudová (2008, p. 11) notes that "the labor market is moving towards increasing flexibility that is, on the one hand, the weakening of the lifelong employment model for an indefinite contract, with a fixed beginning and end of working hours, which brings new possibilities of combination work and private life and expands lifestyle choices. On the other hand, we are witnessing an increase in flexibility forced by 
the employer, requiring the employee to be ready during various day and night hours, a long daily presence at the workplace, or, conversely, involuntary part-time work to reduce costs for employers. Accompanying this flexibility is also a significant reduction in job security."

The topic of market flexibility and job security is also discussed in the European Union. The European Commission comes up with the term flexicurity, which combines flexibility and security in the labor market. It seeks to balance the need for a flexible workforce for employers with the need for job security for employees through four principles of flexicurity: flexible and reliable contractual arrangements; comprehensive lifelong learning strategies; effective active labor market policies and modern social security systems (European Commission, 2007).

According to Frantikova et al. (2020) alternative working hours contribute to the reconciliation of work and personal life, the so-called Work-Life Balance. Women who return to work after parental leave are most interested in them, as well as those who want to take care of their aging or sick relatives, but also those who have no obligations but want to improve their qualifications by studying at work.

Currently, there are many forms of flexible work, often involving different combinations and interpretations (Brenke, 2016). In this context, it is necessary to define the term home office as it is perceived or used for the purposes of the presented contribution. Although it might seem relatively simple and clear, it is not. In the professional literature and among the public, there may be various designations for "out of office" work. Most often we talk not only about home office, but also, for example, about homeworking, teleworking, satellite office, mobile teleworking (Sládek; in: Kučírek et al., 2017, Belzunegui-Eraso \& ErroGarcés, 2020, Baruch, 2001), outworking, tele-homworking (Duffková, 2006, Morgan, 2004). All these and other possible designations usually try to specify the specific predominant places of work outside the specific place specified by the employer, which in our opinion is currently relatively difficult, due to variety and frequent changes, or the intertwining of different activities in the workload of employees working "out of the office ". Another complication in precisely defining the nomenclature and content that lies behind different names, may be that work outside the employer's premises may be called a similar activity in different companies or enterprises.

We understand the term home office for the purposes of the presented paper as stated by Hallman et al. (2021), i.e., that it is an office, administrative (incl. data processing) work performed by an employee mainly from the employee's private environment, most often from his place of residence. It is assumed that the employee is not assigned any specific job or office on the employer's premises during the performance of his work. The term also includes nuances and combinations of, for example, partial field work or various other spaces outside the specific location specified by the employer, as stated by Holgersen et al. (2021). In practice, the specific place of office work is often largely determined by the employee himself.

We chose the term home office as partially unifying due to the fact that it is widely used in the Czech environment and perceived by most of the population just as defined in the text above. Less often used, but identical in its meaning, could also be the concept of homeworking, which defines Reuschke (2021).

At present, it is possible to talk about work in the form of a home office as a functioning way of performing work with growing tendencies. However, it is appropriate to consider trends in the home office in connection with the setting up of the employment system that prevailed in the most developed countries before its inception so that it is possible to understand why similar developments occur at all and how the "traditional" employment model affected the current state and how it could have influenced the current development, claim Predeteanu-Dragne et al. (2020) and Kim \& Parker (2020).

Rosulek (2015, s. 56) makes the following summary commentary on the issue, which enshrines the shift in the employment of people: "The dominant model of managing people's activities is gradually reaching a dead end. The managerial approach of sugar and whips (rewards and punishment) ceases to work effectively for today's generation, and the methods introduced since the Industrial Revolution must change completely." To some extent, the author criticizes the possible benefits of the previously held model of remuneration or, conversely, punishments directed towards adult employees by their superiors. At the same time, it draws 
attention to the fact why for the current (and very probably also future) generations of employees, the idea of a similar pattern of an adult in life ceases to be satisfactory.

A survey commissioned by LMC revealed that the most common forms of flexible working in the Czech Republic are part-time work (i.e., 60\%), flexible working hours (i.e., 45\%) and a combination of working from home with work at the office (i.e., $14 \%$ ). The most common reasons for not using flexible working hours include the nature of work activities or the unusability and unnecessary nature of these jobs (Kocourek, 2011).

Formánková (2011, pp. 80-82) states that there are several reasons or myths that justify the fact that the number of flexible working hours in the Czech Republic is low. These include, for example, salary levels that would be economically unacceptable to most families due to part-time work. Flexible forms of work are often perceived as a type of benefit that causes a reduction in remuneration in other areas or are used by employees without ambitions. It often happens that flexible regime include lower positions and less favorable salary conditions. Another myth is the loss of control over the team. Mui et al. (2021) state that the biggest obstacles to the introduction of flexible working hours include middle management distrust, which includes, among other things, fears of reduced efficiency, impaired communication, slowing down the transfer of knowledge in the team, loss of direct control and influence on subordinates' work. Krummacker (2011, p. 87) includes long parental leave, lack of places in kindergartens and a historical connection among the possible reasons. However, she considers the willingness of superiors and the negotiation skills of employees to be one of the most important factors. She also notes that these alternative forms of work are made possible primarily for managers or specialists.

Developments in employment are linked to societal changes, when the generation of people referred to as "ys" (i..e people born after 1976) is no longer willing, like their parents, to accept the demands, instructions, regulations and control of employers at the heart of their lives (Pendergast, 2010). The new generation is much more acutely aware of the importance of relationships, personal satisfaction, as well as personal employment, and their demands for freedom in the performance of work duties are high (Rosulek, 2015). The interest of researchers in the topic of successful management of work and family life around the world is only confirmed by Shaffer, Joplin and Hsu (2011), Delecta (2011), Lockwood (2003), Picton (2021), Hakansson at al. (2021) or Ma (2021).

At present, it is possible to find work from home in a number of professional sectors, both large companies and small entrepreneurs. Exceptions in this respect are not $\mathrm{Czech}$, but also foreign companies operating in the Czech Republic, which is confirmed by Hanzelková (2013), Bonham et al. (2001) or Coutts (2004). For workers earning on the basis of work activities run from home, it is no exception that they perform several different activities for several different suppliers / employers, which is confirmed by Hanzelková (2013), Vrchota et al. (2020) or Reuschke (2019).

The Czech Labor Code does not operate directly with the term "work from home", the attentive reader will find that in a given legislative regulation it is not possible to meet with a similar phrase, or with another possible concise terminology. Similarly, the Czech Labor Code does not work with the internationally and generally used term "home office", nor with other foreign language equivalents already mentioned in the previous text. Nevertheless, according to Pemová \& Ptáček (2013), working from home is sufficiently regulated for the conditions of the Czech Republic. The authors make it clear in their book that "there is no need to worry about a given form of work activity". Thus, although 'home office', 'teleworking' or 'homeworking' are not directly talked about, it is possible to see the entrenchment of the possibility of performing work duties in a different place than what is specified for a particular employee's employment contract. Rosulek (2015) on the topic of the relationship between the Labor Code and homeworking further states that regardless of the employee's place of work, it is always necessary to take into account, in particular, $\$ 317$ regulating so-called "special work". This is necessary to follow in the case of performing work from home, at the clients, or even when working remotely. It is precisely the paragraph mentioned in the previous paragraph that clearly points to the fact that the Czech Labor Code does not create obstacles for 
home office, but on the contrary provides for a similarly flexible form of employment, as it is possible to find conditions related to of his home (Rosulek, 2015).

Working from home offers many benefits, as stated in Snyder et al. (2021) study. The employer tends to have lower costs with these employees in the form of rent, energy, or technical equipment. Thanks to higher employee satisfaction, there is also reduced fluctuations. The advantages of employees include the possibility of a better work-life balance, saves time that they would otherwise spend commuting, working hours are more flexible. Employees can also literally "create" their work environment and often have more peace of mind at work at home. This work can have a motivational aspect for some employees, employees are more satisfied, their performance often improves. From the point of view of society as a whole, it is also worth mentioning the positive impact on the environment, as these employees do not have to commute to work by means of transport or to enable the employment of disabled or otherwise disadvantaged workers.

However, working from home also poses certain disadvantages or risks for both employers and employees. In particular, employees working from home can be accompanied by certain negative sociopsychological contexts that can affect the psyche of these individuals, but also affect the situation within the team. In the case of work from home, direct superiors tend to have higher demands on employee management, planning and coordination. Direct control is lost and working contacts are less frequent. The costs are incurred primarily to provide means of communication (Snyder et al., 2021).

Working from home is also not for all types of occupations and not for all workers at all. Disadvantages faced by employees working from home include the need to provide equipment, not always and not all equipment is provided by the employer. In addition to a computer, modem and telephone, a copier or scanner may be needed for work, as well as a desk or office chair. It is necessary to provide the necessary space, which can sometimes be a problem, especially in smaller apartments. These employees also face many risks, which represent possible overload, social isolation, loss of belonging or higher demands on work organization. It is also important to mention that when working from home, it is more difficult to draw the line between work and leisure (Kim \& Parker, 2020).

Often the possibility of working from home is associated with trust, homework is often associated with the status of a certain privilege. For example, Ellison (2004, p. 95) states that from the point of view of organizational culture, the concept of trust between employee and superior becomes characteristic and important in the case of home office. If there was already a lack of trust between them, then this distrust increased even more thanks to the home office, the documentation of activities was increased, more emphasis was placed on measurable criteria and feedback.

It is obvious that otherwise working from home will affect an employee who is used to working alone, and otherwise someone who works in a team or work group.

It is possible to assume that while the activity, goals or structure of job positions and roles usually do not change with the shift to a home office, personal contacts between co-workers are no longer so frequent and may even be limited. Social relationships can be transformed due to the absence of workers. The workplace can be considered common only to a certain extent. Workers who work from home can consider their home as a workplace. Awareness of belonging to a group can also change, especially for workers who work largely from home, it can be assumed that after some time they will no longer identify so much with the group.

The transition to flexible working hours and home office is a big change for both employees and employers. Employees are learning how to be productive at home, and employers are trying to find ways to keep their employees motivated to work. "However, the productivity and satisfaction of home office workers is associated with yet another factor: commitment." (Pruden, 2011). Hlušička (2020) also writes about the difficulties with motivation and increased demands on employees and employers.

Pruden (2011) first mentions emerging of special employee benefits that employees can use with their families. These include group and individual fitness and wellness courses, which employees join from home, as well as Netflix subscriptions, various vouchers for online seminars or free minutes for calling with other colleagues. 
Another way to keep employees engaged, according to the author, is their creative involvement, for example, by sharing messages or mutual advice on how to be more productive at home office, or by sharing photos and videos from the new work environment. This fact was discovered by Na Homes.com in cooperation with its employees. Employees thus remain in contact with their colleagues and strengthen mutual relations with them.

Employee support should also come from management itself. This support can take place, for example, in the form of audio / video meetings, during which the employee can confide in his problems and needs (Pruden, 2011). The form of online meetings may also be related to another form of motivation, which Hlušička (2020) writes about, and which is based on management. This form consists of management communication, which often focuses on how employees should do their work, rather than emphasizing the specific impacts of work, how employees' work affects their surroundings and why it is important. The employee then feels more important.

Pruden (2011) also mentions the possibility of interactive meetings used by Wokrswell. Employees are actively involved in meetings - formulating feedback, praising, or sharing their observations, both during and at the end of the meeting. Ryba et al. (2021) further points to the importance of the clothes worn by the employee during working hours. Although it does not seem so, clothes also affect a person's psyche. If an employee changes from his home clothes to his work clothes, he will direct his mind to work and will focus on it even better, regardless of the environment in which he is currently located.

The motivation of employees at the home office can also be influenced by the content of their work and the overall shift and improvement. Hlušička (2020) claims that if an employee feels improvement, he or she feels job satisfaction, and this motivates them further.

The employer should be able to assign work to the employee that will be a challenge and motivation for the employee as well. If it was too demanding for him, it could have the opposite effect. According to him, independence and a certain degree of freedom also help to improve and increase the level of employee engagement, when employees come up with their own solutions and are thus much more creative.

Personal self-motivation is also a form of employee motivation. Self-motivation can be defined as "the effort to incorporate emotions into our thinking and actions so that they lead to the acquisition of knowledge, creativity and success in general" (Suchý et al., 2016, s. 61).

To attain a certain degree of self-motivation, one needs to understand the purpose and deeper meaning of one's task. Self-motivation can be perceived in two forms. In the first form, it is the enthusiasm of the employee for the realization of the goal, which manifests itself as the fulfillment of the task in the best possible way according to the abilities of the employee. In the second form, it is self-motivation from the knowledge that the task must be performed, regardless of the personal attitude of the employee (Suchý et al., 2016, s. 62).

The issue of home office is common abroad, but at the scientific or academic level it is still not sufficiently researched, as evidenced by the lack of information sources and scientific studies from before 2021, even in the last year there is no noticeable increase in scientific research of home office issue, its benefits and disadvantages. This is also one of the reasons for carrying out our research.

\section{Research Methodology}

The aim of the presented paper is to answer the research question: How does home office work affect employee motivation?

Due to the fact that the research question itself does not usually cover the whole research problem, it is usually further divided into several other specific questions (Švaříček et al., 2014). Using partial questions, we found out how the interviewed employees perceive work in the form of a home office, what they see as advantages and disadvantages, or what motivates or demotivates them in this area and how important the home office is for them in the field of motivation. 
For the implementation of the survey, we chose a qualitative method in the form of semi-structured interviews. This is probably the most common method, as it addresses many of the disadvantages of unstructured or fully structured interviews (Miovský, 2006). We wanted to avoid overly guiding questions, our own stereotypes, prejudices, and our own bias on the topic as much as possible. Semi-structured interviews gave us the opportunity, unlike other research methods, to listen and think about the answers of respondents and the communicated information in a broader context, including the opportunity to observe non-verbal expressions of respondents (observation method). We perceive as a great advantage of the chosen method the possibility to ask the respondents additional questions, not only for supplementing specific information, but also for their deeper understanding. At the same time, the method allowed us a great deal of freedom in conducting the interviews themselves and the ability to respond to specific answers. In semistructured interviews it is possible to change the order of questions as needed, differentiate (change strategies), lead some passages in a more structured way and leave others to the interviewee (Miovský, 2006). The stated advantages of the used method fully satisfied the fulfillment of the aim of the work.

All interviews were arranged in advance and took place in an informal atmosphere, most often in a home environment. Two interviews took place in the interviewer's home, one interview took place in the interviewer's corporate office and the others in the interviewee's home. In several cases, directly in the premises used for their work in the form of a home office. We paid due attention to the external environment, as recommended by Miovský (2006), which means that the environment corresponded to the research objectives and the nature of the questions asked. All respondents had basic refreshments at their disposal, were not significantly disturbed by the surroundings during the interviews and were not in a time crunch. The interviews were recorded on a recording device with the consent of the respondents, for the possibility of data processing and subsequent analysis. The indisputable advantage of such recorded data is their authenticity, complexity and "represents a significant help for the researcher" (Miovský, 2006, p. 197).

The selection of respondents was carried out by the method of intentional selection. The research sample was 90 respondents who have specific experience with working from home, that is, they used or are using work from home, i.e., home office, as a benefit, standard or primary place of work. All respondents in the period under study, when they used the home office, were in an employment relationship or a contractual relationship with one primary employer on a full-time or part-time basis. An important aspect of the research is the fact that all respondents worked in the home office regime before the outbreak of the COVID-19 pandemic, potential respondents who used the home office precisely as a result of the pandemic were excluded from the research.

The interviews took place between 22.10.2020, when the first pilot interview took place, until 17.12.2020, when the last interview took place. One interview was conducted with each respondent in the time range of 25 to 35 minutes. The average length of all interviews was 29 minutes. Of the total number of respondents, 34 were women and 56 were men. The average age of the respondents was 42 years, ranging from 31 to 52 years. All respondents live in the same household with their partner or spouse and at the same time with at least one minor child. Respondents most often stated that they work in the field of administration, finance, marketing, sales, education, or accounting, i.e., in fields where a daily presence at the employer's workplace is not required and where it is possible to work and communicate through ICT technology without difficulty.

\section{Results and Discussion}

The term "home office" was known to all participants in the research. The possibility to work partly from home is considered as a benefit and for $78 \%$ of respondents it can clearly influence the choice between job offers.

The condition for working from home is the use of ICT technologies. These technologies are used in the Czech Republic by $98.7 \%$ of companies with more than 10 employees, and the most used are desktop computers (92.2\%), smartphones (91.2\%) and laptops or tablets (87.3\%) (CZSO, 2021). Employers most often provide laptops (64\%) and mobile phones (31\%) to their employees for work from home. Conversely, 
$13 \%$ of employers do not provide ICT technology to their employees at all, which can be a big problem if the home office is mandatory for employees. It was the quality equipment for work that the respondents (4) mentioned in the penultimate open-ended question, where they were asked what would motivate them more to work.

Home office has a number of advantages, but also disadvantages. The main advantages may be a higher degree of freedom and independence, scheduling the work schedule according to your needs, saving time and money for transport, creating your own work environment or more time spent with the family (Hubinková, 2005, p. 176). Respondents of our research appreciated these benefits as follows:

Planning of the schedule according to their needs (26.4\%),

Save time and money on transport (25.8\%).

Higher degree of freedom and independence (23.6\%).

Creating own work environment (12.2\%).

More time spent with family (12.1\%).

On the contrary, the disadvantage may be the urge to work beyond working hours / duties, the intertwining of personal and working life, lack of contact with colleagues or superiors, lack of personal communication or complications of making new contacts, especially with new employees (Hubinková, 2005, p. 176).

Our respondents assessed these disadvantages as follows:

Interweaving work and private life $(28.2 \%)$,

Lack of contact with colleagues (21.5\%),

Urge to work beyond working hours / duties (17.1\%),

Absence of personal communication (12.6\%),

Complications with establishing contacts (11.2\%).

Lack of contact with a superior $(9.5 \%)$.

Focusing on these disadvantages and trying to compensate for something can increase employee satisfaction.

Employee satisfaction at work from home can be examined from different angles. According to research by the Ministry of Labor and Social Sciences (Esfce.cz, 2020), 60\% of employees are satisfied with the organization of work at home office, $50 \%$ are better concentrated and more efficient, but only $40 \%$ feel better work motivation. The biggest problems are the effectiveness of cooperation with colleagues and the reliability of technology.

The overall satisfaction of the respondents of our research with home office work reached 6.7 / 10 points and the median value was 7 , so employees were rather satisfied with this form of work performance.

Motivation aims to increase productivity and employee satisfaction. It was with productivity that employees identified at least in personal characteristics. Some forms of motivation can also address the disadvantages that occur due to home office (lack of contact with colleagues or superiors and networking) and which reduced employee satisfaction. We know from our research results thatemployees at work value the most:

Communication with colleagues / good relations in the team $(25 \%)$.

Degree of independence and freedom (possibility to organize their own work) (24.8\%).

Good relations with a superior $(19.2 \%)$.

Opportunity to further education $(16.3 \%)$.

Clearly defined work tasks (14.8\%).

Motivation arises when people move towards a goal that meets their needs (Armstrong, 1999, p. 295). If the work itself satisfies the needs of employees, it is an internal motivation. Employees create the factors themselves, thanks to which they move towards their goal. Various management methods used to motivate employees belong to external motivation, which is more short-term than internal motivation (Armstrong, 1999, pp. 298-299). The most commonly used external motivators include various financial rewards, 
financial bonuses or salary additions. Our research shows that enthusiasm for added money is rather a shortterm affair, as $77 \%$ of respondents said that enthusiasm lasts a maximum of 4 months.

According to Porvazník (2011, p. 83), work motivation is connected with the performance of work activities, the performance of a job position and the fulfillment of the relevant work role. The main reason that motivates people to work is the need to make money and make a living (Nakonečný, 2005, p. 120). According to Štikar's hierarchy of work motivation (Štikar et al., 2003, p. 103), which he compiled on the basis of Maslow's hierarchy of needs, work also serves to fulfill another 46 human needs. The most important is the salary for livelihood, as well as social security, pension security, acceptance by the working group, status symbols, promotion or self-realization. Motivation of employees working from home is more complex than motivation of employees working in the office. Many employees hardly leave home or apartment, making it difficult for them to find motivation to work and work efficiently. At a time when almost all services are closed, employers are looking for new special benefits that they could offer to employees for above standard and well-done work. These benefits can include, for example, online group and individual fitness and wellness courses, Netflix or HBO subscriptions, various vouchers for online seminars, or free minutes for calling with colleagues. Our respondents assessed these special benefits as follows:

Vouchers for online seminars (for further education) (33.3\%).

Online group / individual fitness or wellness courses (31.9\%).

Netflix or HBO subscription (25.9\%).

Free minutes for calling with colleagues $(8.8 \%)$.

Despite the fact that communication and good relations with colleagues are very important for employees, the free minutes ended in the last place. The reason may be personal advantageous tariffs or communications and calls of employees via online platforms (Skype, Zoom...).

Factors that help employee engagement may be their creative involvement in the form of sharing messages or mutual advice on how to work more efficiently at home office or sharing photos and videos from the work environment. These factors also support communication between employees. Employees on our research most often improve mutual communication as follows:

Regular conversations with colleagues (not only for work) (49\%).

Sharing messages $(41 \%)$.

Sharing advice on how to be more efficient at home office (22\%).

Sharing photos from the new working environment (8\%).

Employers can motivate employees through online meetings / video meetings, through which management can better communicate with the employee and reassure them of their importance and the importance of their work for the company. Employee satisfaction can also be increased by choosing the appropriate form of meetings, the correct assignment of work tasks and also the correct nature of tasks, it is important to find out what employees prefer. According to our research, employees prefer online meetings with video, not just listening, and they also prefer interactive meetings that require their active participation, thanks to which they better retain attention. Most respondents also prefer to enter a task with information on how to perform the task rather than why. Employees also motivate and keep active rather complex tasks that they have to think about and have the opportunity to come up with their own solution.

An interesting way to motivate yourself to work and work more efficiently is to adjust your appearance and change into work clothes as if you were going to work. The employee thus directs his mind to work and will focus better on it (Ryba et al., 2021). Rather, our respondents disagreed with this statement. 66\% of respondents feel no or almost no effect on the effectiveness of their work. Only $12 \%$ of respondents agreed with the statement and $21 \%$ rather yes, but the answer was not $100 \%$.

According to Pruden (2011), it is also possible to improve employee engagement by using a unified communication system not only for business communication, but also for personal communication. In the system it is then possible to set weekly / monthly goals, deadlines, important announcements, company events or news, birthdays of team members or information about the current status of the project. This system 
is recommended for smaller work teams. Our respondents evaluated the individual variants, which can be marked as follows:

Regular updating of the current status of the project (59\%).

Setting deadlines in the system (50\%).

Setting weekly / monthly goals (49\%).

Invitations to online corporate events (36\%).

Recording the birthday of team members $(30 \%)$.

Teambuilding can be a good solution for insufficient communication with colleagues and superiors. This problem has been mentioned several times, it took second place in the ranking of disadvantages and at the same time communication with colleagues ranked first in the ranking of what respondents appreciate the most at work. Communication with colleagues helps work motivation to $73 \%$ of respondents. The popularity of teambuilding according to the results of the survey was $7.1 / 10$ points and the median value was 8 , the difference between these values caused a large difference between the answers of the respondents. Most research participants were in favor of organizing online team buildings once every 3 months $(31 \%)$ and once a month (28\%), due to the small difference between the numbers, it could be an ideal solution to organize team buildings once every 2 months. It is important to choose a suitable form of team building that will entertain most employees. Our respondents arranged the above options as follows:

Have a drink online with colleagues $(37.1 \%)$.

Online escape game (31.3\%).

Team online exercises (yoga, pilates) (16.1\%).

Online dinner (15.5\%).

Respondents had the opportunity to make their own recommendations on how to improve work efficiency during home office. Or tell what they miss the most at home office and what would motivate them more to work. Their recommendations could be divided into these categories:

The first category was contact with colleagues. Respondents most recommended:

Smalltalk between work tasks: Smalltalk between work tasks and better communication and cooperation could be solved by sharing messages, calls or introducing a unified communication system.

Team building.

Better communication / cooperation.

Another category was mental balance and development. In this category, respondents most often mentioned:

Own project / improvement / development. This solution can be just more complex tasks, which require employees to think, and they can also come up with their own solutions. It was this solution that was preferred among the respondents.

Small rewards for partial progress.

Snacks / coffee: good solutions given by respondents were small rewards for partial progress and small snacks or coffee for encouragement and light relaxation during working hours.

Respondents also mentioned the work environment. Specifically:

Creating a quiet environment

Music / podcasts in the background.

Our research also discussed and mentioned the connection between the creation of a work environment and the appropriate reconciliation of private and professional life, as well as the organization of work. The motivators that respondents would appreciate or appreciate are also based on employers.

Better financial evaluation.

Praise (feedback).

Clearer procurement of work and its delegation.

Respondents in this category most often mentioned better financial evaluation, but we know from the research results that this form of motivation does not last too long. If the employer were to increase the salary 
of employees every 4 months, because for $77 \%$ of employees enthusiasm would last longer, it would be very costly for him. The second option was praise or feedback, which is free for employers and motivates employees to perform better because they feel better about themselves. The last most frequently mentioned option was a clearer assignment of work and its delegation. This is related to better communication on the part of the employer, which could be solved by a unified communication system or more frequent audio / video calls with a superior.

The last category was the organization of work itself. Respondents are most helped by:

Work planning (daily / weekly plan).

Short-term goals / deadlines.

Freedom to use time (own organization).

The solution can be found in concentrating work in the most active blocks and planning breaks in less active blocks or the introduction of a unified communication system, in which deadlines and short - term goals can be set.

Our research confirmed several areas mentioned by various authors. This is, for example, the positive perception of home office employees in the area of time savings, which is mentioned by Sládek (2017), Biesser et al. (2021) or Toniolo-Barrios \& Leyland (2021) or the feeling of freedom mentioned by Kelly (2020) or Rosulek (2015), which mentions the feeling of freedom as one of the strongest motivators.

In the case of negative, and thus potentially demotivating phenomena, the perception of employees in the field of social isolation, as also mentioned by Sládek (2017), Ipsen et al. (2021) and Aczel et al. (2021). At the same time, this largely confirms the importance of a human motivation, namely the general need for affiliation, as described, for example, by Nakonečný (2004) or Holgersen et al. (2021). The potential risk of employee demotivation could also be posed by superiors, for example due to lack of attention or failure to provide feedback, as mentioned by Urban (2010), Henning et al. (2021) or Kawaguchi and Hiroyuky (2020), as little contact with a superior was also one of the negatives mentioned in the research. The phenomenon of procrastination mentioned by the respondents in several cases could also be mentioned as confirmatory and existing in home office workers, probably in the form described by Ferrari et al. (2021) or that the basic cause of the habit of procrastination in men is especially their self-limiting beliefs (Chung et al., 2020).

The research did not show that employees from home office work with greater intensity than in the office, as mentioned by Gruber (2019) or Zito et al. (2021). Respectively, none of the respondents mentioned this in the interview. In this context, however, it should be noted that $r$ to refute or confirm it, it would probably be appropriate to carry out research, or part of it, focused directly on this area and to make relevant comparisons.

The frustration of low efficiency at work from home, which Rosulek (2015) or Kohara \& Maity (2021) talk about, was not mentioned by the respondents, on the contrary, some stated that they found their work from home more efficient than in the office.

Given the result of part of the research in the field of supplementary questions, we could also talk about confirming the information from the article on the website EuroZprávy.cz, 2019, online that the home office is one of the decisive factors that leads job seekers to decide to accept the offer, as more than half of the respondents actually stated this as a decisive factor.

Overall, based on the results of the research, one could agree with the generalizing statement of Rosulek (2015), Hallman et al. (2021), Holgersen et al. (2021) or Saltiel (2020) that the positives of the home office outweigh the negatives, even in the area of the perception of the home office by the employees themselves. The relatively high financial evaluation of the home office as a benefit on the part of the respondents can also be a confirmation, which could be considered as a summary evaluation in this context.

The results of the research clearly show that home office and the possibility of working from home is a phenomenon that has a significant impact on employee motivation. However, it would not be good to look at it only in black and white and one-sidedly. The home office is sometimes referred to only as a certain benefit and in practice it is often used by employers or viewed by employees. The confirmation can be the personal 
portal www.jobs.cz, already mentioned in the introduction, on which the home office is listed in individual advertisements almost exclusively in the employee benefits section.

The results of the research showed that the perception of home office by individual people (employees) can vary quite significantly, especially in connection with their life situation, current conditions, or the degree of their current motivation and self-motivation. Flattening the home office only for benefit could in practice lead to relatively fatal consequences. Although the home office undoubtedly has a significant positive impact on employee motivation, it can also lead to their demotivation or burnout, which can result in the loss of an employee, as confirmed by an interview with Martin V., who introduced the home office and related demotivation in connection with procrastination as one of the reasons for the planned change of job "Yeah, it happens to me often, it happens to me more and more often, and that is also the reason why I wanted to change jobs or change it." (Martin V., 24th minute). Due to the fact that the home office is often used by employees in the positions of specialists, salespeople or managers, this loss can be quite tangible for the employer and can mean significant, not only financial losses for him.

A relatively interesting finding may be that what respondents state as positive and motivational elements is often interpreted as typical of the so-called "ys" generation, or the "millennials" generation. Not only do all respondents actively use modern technologies in the form of computers, including specific programs and "smartphones", but the answers also attach great importance to the so-called "work life balance", a certain degree of freedom and liberty in performing work tasks, or flexibility of working hours, despite the fact that the majority of respondents move around the upper limit of the mentioned generation "y", as it is interpreted, i.e. people born after 1976.

The combination of home office and at least partial work from the office seems to be a suitable model from the point of view of the place of work, because in the overall context of the research it was noticeable that fewer negatives and risks are seen in home office by respondents who have the opportunity to work from home or to work in the office, either regularly or as needed. At the same time, this combination sounded several times as an ideal model from the respondents' mouths. In our opinion, this model can relatively well eliminate a large part of the risks and negatives.

It can be assumed that the current situation around the COVID-19 pandemic is most likely to change the approach of some employers and employees to the possibilities of using the home office in the future. This could also be a good reason for further research in this area.

\section{Conclusion}

The presented paper focused on the phenomenon of home office, both in its broader concept and especially in the area of its influence on employee motivation.

Home office is widely used for a variety of reasons, but its popularity has grown significantly as a result of the global COVID-19 pandemic, which erupted in late 2019 and spread around the world in 2020 and 2021. The pandemic affected the functioning of probably all organizations around the world, and many companies were forced to switch to home office to reduce the transmission of the virus by limiting physical contact with people. Motivation of employees is thus much more difficult for employers than before, however, it still remains crucial for companies. Properly motivated employees are more efficient and employee performance is directly related to the performance of the entire company. If employees are motivated enough, they are more productive, and at the same time their work is much better than that of non-motivated employees. In addition, satisfied employees do not tend to change jobs. It is easier for the company, and much less financially expensive, to invest in existing employees and keep them satisfied than to look for new employees, which they must then train and introduce into work processes. The company's goal should therefore be to find a way of motivation that will be most effective for its employees, and at the same time as cost-effective as possible for the company. From a search of relevant sources, for example Garrote Sanchez et al. (2021), Delventhal et al. (2021) or Bloom (2014), it was possible to gain awareness of how a home office can be classified in general in terms of the historical development of the approach to fulfilling the 
duties of employees. These sources mention, and we confirm this, an absolutely fundamental and unforgettable contribution, especially of modern computer and communication technologies, which with their development since the 1970s have made the home office today a possible option for workers.

A search of relevant sources, as well as our research, showed that work in the form of a home office has a significant effect on employee motivation. It could be said that most employees perceive the home office rather positively and perceive this form of work as a certain benefit provided by the employer. The analysis of the data also shows that probably the biggest motivator for working from home in the form of a home office is employee flexibility in the form of private and working time management and related work and extracurricular activities, including feelings of freedom, childcare and work on maternity leave. Other motivating elements may also be for some employees, for example, greater peace of mind, higher work efficiency, saving time and money for travel, the advantage of the home environment, less stress, or the confidence of the employer.

The results of the research show that the possibility of working from home has a relatively significant financial value for specific employees, even in comparison with other benefits normally provided by employers. The home office is also likely to serve as a competitive advantage for employers, as some employees may prefer job offers that offer the opportunity to work from home.

Despite the indisputable positives, it must be stated that there are a number of negatives, risks and threats associated with the home office. The research show that various factors can have a negative effect on employee motivation. The strongest negative factor seems to be the reduced contact with colleagues in the workplace, which can have a negative effect either in the area of social isolation itself or in the area of access to information. The mentioned isolation is also related to lower contact with the superior and the associated absence of providing feedback. Another important demotivating element can be an unsatisfactory working environment, which results, for example, from interference at work by other members of the household, including children, unsatisfactory working conditions in the form of aids, or unsuitable working space. One of the significant threats to work in the form of a home office with a direct impact on employee performance is undoubtedly the risk of procrastination.

We listed above the factors that affect either positively or negatively the home office, thus we answered the research question formulated by us. In this context, however, it is necessary to further formulate proposals and recommendations for the implementation of home office in companies of various specializations and sizes. These recommendations are as follows: Work results, tasks and goals should be measurable and clearly defined. Their control should be ensured; Within the home office provision system, equal and clear conditions should be set for all employees, or the rules and conditions for the provision of home office in individual departments should be specified in separate documents. The recommended frequency of work from home is 1 to 2 days a week.

Employees working from home should be provided with the necessary technical and other equipment, in particular the provision of home calling software. In the case of regular work, the company should then provide a financial contribution; Employees should be acquainted with the home office system, e.g. in the form of webinars, and a meeting or workshop could be organized for managers, where they would be provided with training in employee coordination and could also exchange their experiences; Managers should be allowed to remove certain employees from the home office under certain clearly defined conditions, they should be supported in particular in the internal directive for the home office; The rules and conditions set out in the home office directive should be complied without exception. The company should also emphasize the provision of health and safety.

The results of the presented paper show that it would be a mistake to look at the home office only from one side. Although it could be said that the positives of this type of work on employee motivation outweigh the negatives, this ratio may vary significantly from employee to employee, especially depending on the specific and current conditions on the part of individual employees, which may also change significantly in time. The home office can be a strong motivator, which can be used very well and effectively, as well as it 
can become a very strong demotivator, which can cause considerable problems and losses on the part of both the employer and the employee. In this context, the basic assessment of the suitability of an employee's work in the home office regime seems to be a timely response to current internal or, conversely, external stimuli, which are motivating factors for him. The topic of the correlation of employee motivation and home office is currently very topical, to examine the issues addressed, it would be interesting to examine in more depth the individual correlations. Further focus of research could be on identifying the psychological context of working from home, it would clearly be very interesting to examine how the socio-psychological context changes depending on age, gender, number of years in company or job position. Presented paper is one of the outputs of the project 1/0021 / Identification of Factors Motivating Certified Project Managers to Perform during COVID 19 Pandemic Home Office supported by VEGA, Slovakia.

\section{References}

Aczel, B., Kovacs, M., van der Lippe, T., \& Szaszi, B. (2021). Researchers working from home: Benefits and challenges. PloS one, 16(3), e0249127.

Michael, A. (2007). Human Resource Management: Latest Trends and Practices-10. edition. Grada Publishing as.

Baruch, Y. (2001). The status of research on teleworking and an agenda for future research. International journal of management reviews, 3(2), 113-129.

Belzunegui-Eraso, A., \& Erro-Garcés, A. (2020). Teleworking in the Context of the Covid-19 Crisis. Sustainability, 12(9), 3662.

Bieser, J. C., Vaddadi, B., Kramers, A., Höjer, M., \& Hilty, L. M. (2021). Impacts of telecommuting on time use and travel: A case study of a neighborhood telecommuting center in Stockholm. Travel Behaviour and Society, 23, 157-165. Bloom, N. (2014). To raise productivity, let more employees work from home. Harvard Business Review, JanuaryFebruary.

Bonham, S., Beichner, R., \& Deardorff, D. (2001). Online homework: Does it make a difference?. The Physics Teacher, 39(5), 293-296.

Brenke, K. (2016). Home office: Possibilities are far from being exhausted. Diw weekly report, 83 (5), 95-105.

Chung, S. J., An, H., \& Suh, S. (2020). What do people do before going to bed? A study of bedtime procrastination using time use surveys. Sleep, 43(4), zsz267.

Coutts, P. M. (2004). Meanings of homework and implications for practice. Theory into practice, 43(3), 182-188.

CZSO: Use of information and communication technologies in the business sector in 2011.

Delecta, P. (2011). Work life balance. International Journal of Current Research, 3(4), 186-189.

Delventhal, M. J., Kwon, E., \& Parkhomenko, A. (2021). JUE Insight: How do cities change when we work from home? Journal of Urban Economics, 103331.

Dudová, R. (2008). New opportunities and risks. Work flexibility, marginalization and private life in selected occupations and social groups. Prague: Institute of Sociology AS CR, vvi .

Duffková, J. (2018). Homework, telework, etc. (or too many "works"). Auc Philosophica Et Historica, 2004 (1), 105 124. European Commission. Flexicurity [online]. Brussels, 2007 [cit. 2021-01-22]. Retrieved from http://ec.europa.eu

Ferrari, J. R., Swanson, H. L., \& Patel, D. A. (2021). The Impact of Office Clutter on Remote Working:" I Can't Work with All This Stuff!". North American Journal of Psychology, 23(1).

Formánková, L. (2011). Flexibility in Czech companies. HR Management, vol. 7, no. 2, pp. 80-83.

Frantikova, Z., Vlckova, M., Vrchota, J., \& Sladek, J. (2017). Comparison of homeworking in the Czech Republic and Spain. Economic and Social Development: Book of Proceedings, 693-700.

Daniel, D., Nicolas, N., Ozden, C., Rijkers, B., Viollaz, M., \& Winkler, H. (2020). Who on earth can work from home? The World Bank.

Gruber, J. (2019). How to learn to work from home? Firmnívzdělávání.eu

Håkansson, C., Leo, U., Oudin, A., Arvidsson, I., Nilsson, K., Österberg, K., \& Persson, R. (2021). Organizational and social work environment factors, occupational balance and no or negligible stress symptoms among Swedish principals-a cross-sectional study. BMC Public Health, 21(1), 1-9. 
Hallman, D. M., Januario, L. B., Mathiassen, S. E., Heiden, M., Svensson, S., \& Bergström, G. (2021). Working from home during the COVID-19 outbreak in Sweden: effects on 24-h time-use in office workers. BMC public health, 21(1), $1-10$.

Hanzelková, A. (2013). Personnel strategy: step by step. CH Beck publisher.

Henning, H., Zhiyang, J., \& Simen, S. (2021). Who and how many can work from home? Evidence from task descriptions. Journal for Labour Market Research, 55(1).

Hlušička, P. (2013). Motivation of employees. Corporate sociologist

Holgersen, H., Jia, Z., \& Svenkerud, S. (2021). Who and how many can work from home? Evidence from task descriptions. Journal for labour market research, 55(1), 1-13.

Hubinková, Z. (2008). Psychology and sociology of economic behavior.

Ipsen, C., van Veldhoven, M., Kirchner, K., \& Hansen, J. P. (2021). Six key advantages and disadvantages of working from home in Europe during COVID-19. International Journal of Environmental Research and Public Health, 18(4), 1826.

jobs.cz (2021). "Job offers" search engine.

Kawaguchi, D., \& Hiroyuki, M. (2020). Who can work from home? The roles of job tasks and HRM practices. Center for Research and Education in Program Evaluation. Discussion Paper, (82).

Kelly, J. A. (2020, June). Work-in-Progress-The Sudden Requirement to Work from Home Due to COVID-19 Pandemic Restrictions: Attitudes and Changes in Perceived Value of Physical and Immersive Workspaces. In 2020 6th International Conference of the Immersive Learning Research Network (iLRN) (pp. 385-388). IEEE.

Kim, N. K. N., \& Parker, S. C. (2020). Entrepreneurial homeworkers. Small Business Economics, 1-25.

Kocourek, J. (2011). LMC: $58 \%$ of companies offer flexible jobs in specialized positions.

Kohara, M., \& Maity, B. (2021). The Impact of Work-Life Balance Policies on the Time Allocation and Fertility Preference of Japanese Women. Journal of the Japanese and International Economies, 60, 101134.

Krummackerová, P. (2011). Work-Life Balance in Germany. HR Management, vol. 7, no. 2, pp. 84-87.

Law No. 262/2006 Col., Labour Code. online. Retrieved from: https://www.zakonyprolidi.cz/cs/2006-262

Lockwood, N. R. (2003). Work/life balance. Challenges and Solutions, SHRM Research, USA, 2-10.

Ma, J., Ollier-Malaterre, A., \& Lu, C. Q. (2021). The impact of techno-stressors on work-life balance: The moderation of job self-efficacy and the mediation of emotional exhaustion. Computers in Human Behavior, 122, 106811.

Mehnert-Theuerkauf, A. (2020). Those Meetings Really Could all have been E-Mails. Psychotherapy, Psychosomatics, Medical Psychology, 70 (8), 317-318.

Miovský, M. (2006). Qualitative approach and methods in psychological research. Grada Publishing.

Morgan, R. E. (2004). Teleworking: an assessment of the benefits and challenges. European Business Review.

Mui, S., Reardon, E., Andric, A., \& Sinha, B. (2021). 2020 Office Quarantine. The Journal of Structured Finance, 26(4), 25-41.

Finally, M. (2005). Social psychology of organization. Grada Publishing.

Finally, M. (2014). Behavior motivation. Prague: 1st edition. Stanislav Juhanak - Triton. ISBN 978-80-7387-830-6.

Nový, I., Surynek, A. et al. (2006). Sociology for economists and managers. Prague: Grada Publishing.

Terezie, P., \& Radek, P. (2013). Private and corporate kindergarten from A to Z: how to establish and operate a private or corporate preschool facility. Grada Publishing as.

Pendergast, D. (2010). Getting to know the Y generation. Tourism and generation Y, 1, 1-15.

Picton, A. (2021). Work-life balance in medical students: self-care in a culture of self-sacrifice. BMC Medical Education, 21(1), 1-12.

Porvazník, J. (2011). Charisma-leadership versus holistic (synergetic) competence of the managers. Journal of Competitiveness.

Predeţeanu-Dragne, D., Tudor, I., Popescu, D., \& Nicolae, V. (2020). Is Homeworking a Better Option in the Digital Era? An Empirical Research across EU Member States. European Journal of Sustainable Development, 9(4), 109-109.

Pruden, H. (2011). The Three Skills of Top Trading: Behavioral Systems Building, Pattern Recognition, and Mental State Management (Vol. 291). John Wiley \& Sons.

Reuschke, D. (2019). The subjective well-being of homeworkers across life domains. Environment and Planning A: Economy and Space, 51(6), 1326-1349.

Reuschke, D., Mason, C., \& Syrett, S. (2021). Digital futures of small businesses and entrepreneurial opportunity. Futures, 128, 102714. 
Rosulek, M. (2015). Teleworking as an effective method of work. Digital nomads. online. Retrieved from: https://digitalninomadstvi.cz/prace-na-dalku-jako-efektivni-metoda-prace/

Russo, D., Hanel, P. H., Altnickel, S., \& van Berkel, N. (2021). Predictors of well-being and productivity among software professionals during the COVID-19 pandemic-a longitudinal study. Empirical Software Engineering, 26(4), 163.

Ryba, T. V., Ronkainen, N. J., Douglas, K., \& Aunola, K. (2021). Implications of the identity position for dual career construction: Gendering the pathways to (Dis) continuation. Psychology of Sport and Exercise, 53, 101844.

Saltiel, F. (2020). Who can work from home in developing countries. Covid Economics, 7(2020), 104-118.

Shaffer, M. A., Joplin, J. R., \& Hsu, Y. S. (2011). Expanding the boundaries of work-family research: A review and agenda for future research. International Journal of Cross-Cultural Management, 11(2), 221-268.

Sládek, P. Information technology and psychological aspects of teleworking; In: Kučírek, J. et al. (2017). Applied psychology: selected topics: teleworking, leadership, social psychological training. Prague: City.

Snyder, K., Rech, J. P., Masuda, K., \& Dinkel, D. (2021). Perspectives of infant active play: a qualitative comparison of working versus stay-at-home parents. BMC public health, 21(1), 1-9.

Štikar, J., Rymeš, M., Riegel, K., \& Hoskovec, J. (2003). Psychology in the world of work. Karolinum.

Suchý, J., Papánek, P. \& P. Náhlovský (2016). The six pillars of managerial success: how to strengthen, develop and use them in managerial and personal life. Prague: Grada, 2016.

Švař́íček, R., Šed'ová, K. et al. (2014). Qualitative research in pedagogical sciences. Prague: Portal. ISBN 978-80-2620644-6 32.

Toniolo-Barrios, M., \& Pitt, L. (2021). Mindfulness and the challenges of working from home in times of crisis. Business Horizons, 64(2), 189-197.

Urban, J. (2010). 10 most expensive managerial mistakes. Grada Publishing as.

Vrchota, J., Maříková, M., \& Řehoř, P. (2020). Teleworking In Small and Medium Enterprises (SMES) Before the Onset of Coronavirus Crisis in The Czech Republic. Management: Journal of Contemporary Management Issues, 25(2). Zito, M., Ingusci, E., Cortese, C. G., Giancaspro, M. L., Manuti, A., Molino, M., ... \& Russo, V. (2021). Does the End Justify the Means? The Role of Organizational Communication among Work-from-Home Employees during the COVID-19 Pandemic. International Journal of Environmental Research and Public Health, 18(8), 3933. 